Open Access

\title{
A study on the dynamic comparison of logistics industry's correlation effects in China
}

\author{
Shaohua $\mathrm{Yi}^{{ }^{*}}$ (D) and Jie $X i \mathrm{e}^{2}$
}

\author{
* Correspondence: \\ yishh@cass.org.cn \\ ${ }^{1}$ Circulation Industry, Financial \\ Strategy Institute, Chinese Academy \\ of Social Sciences, Beijing, China \\ Full list of author information is \\ available at the end of the article
}

\begin{abstract}
Background: Entering the middle and late period of 1990s, the logistics industry has been keeping high-speed growth along with China's continuously increasing economic level. As a basic and strategic industry, the logistics industry is closely linked with and influenced by other industries while influencing them. It plays an irreplaceable role in ensuring smooth operation of the national economy and satisfying the demand of consumers. Its development level directly affects that of the national economy.

Methods: With input-output tables from 1997 to 2010, the input-output model was used to measure the association effect between the logistics industry and its related industries and to calculate the dynamic degree of influence logistics industry exerts on relevant industries at the different periods.
\end{abstract}

Results: According to the input-output analysis, we found results as follows. (1) the status of logistics industry remains to be further promoted. (2) The logistics industry turns into one with "low added value and strong leading force." (3) Industrial logistics is the main trend while logistics of service industry change. (4) The logistics industry is closely linked with the second industry.

Conclusions: To promote the sustained healthy development of logistics industry and give full play to the role of logistics industry in the national economy, the authors then put forward countermeasures and suggestions: (1) Develop third-party logistic in order to promote the socialization and specialization level of logistics distribution. (2) Speed up the development of electronic business logistics, set up reasonable layout of transportation infrastructure, and build entitative logistics network. (3) Accelerate the logistics informatization and standardization and improve management and service levels of logistics enterprises.

Keywords: Logistics industry, Correlation effect, Dynamic comparison

\section{Background}

Since 1990s, great progress has been scored in China's logistics industry and its position is being improved constantly. In particular, it plays an important role in promoting industrial structural adjustment and transformation of economic growth mode. Since 1997, in the aspects of the total amount of social logistics and growth (see Fig. 1), the year-on-year growth rate remains at about $20 \%$, except for the sharp decreases of total social logistics growth rate during the Asian financial

(c) The Author(s). 2017 Open Access This article is distributed under the terms of the Creative Commons Attribution 4.0 International License (http://creativecommons.org/licenses/by/4.0/), which permits unrestricted use, distribution, and reproduction in any medium, provided you give appropriate credit to the original author(s) and the source, provide a link to the Creative Commons license, and indicate if changes were made. 
crisis in 1998 and 2009 due to the impact of global financial crisis. After 2011, as our country's economic development enters into a period of downward development, the national economy is in a special period in which three features of "shifting growth rates, implementing the policy of structural adjustment and working out the early stimulation policy" overlap and the logistics industry's growth began to slow even though the growth of added value exceeds that of GDP. This shows the logistic industry is amid a period of fast growth.

Seeing from the composition of total social logistics (see Fig. 2), the proportion of industrial goods' logistics in total logistics had been obviously increasing continuously from 1997 to 2015. The share of logistics for the goods of units and residents had also witnessed an increasing trend, while the shares of logistics taken by agricultural products and imported goods had been decreasing continuously. The share by renewable resources' logistics had been changed a little. The above reflects first a fact that the composition of our logistics industry changes with changing economic structures at different economic development stages and the absolute dominant position of Chinese industrial goods' logistics.

Judging from the total expenditure of social logistics (see Fig. 3), the proportion of total social logistics in GDP has been decreasing year by year although its absolute value had been on the rise. The trend of sharp decreases in year-on-year growth rate from 2012 has indicated that the operation cost of our country's social logistics has been lowered steadily.

Seeing from the added value of the logistics industry and its year-on-year growth rates (see Fig. 4), from 1997 to 2014, the growth rate of the added value of China's logistics industry has basically exceeded GDP growth rate of the same period. Since 2007, affected by financial crisis, logistics industry has witnessed a slowing growth rate in its added value that is still higher than GDP growth.

From the proportion of the added value of the logistics industry in GDP and the tertiary industry (see Fig. 5), the share of added value of China's logistics industry in GDP has been basically stable, hovering around $7.0 \%$. The trend for the proportion of the added value of the logistics industry in the tertiary industry is basically consistent with that of GDP.

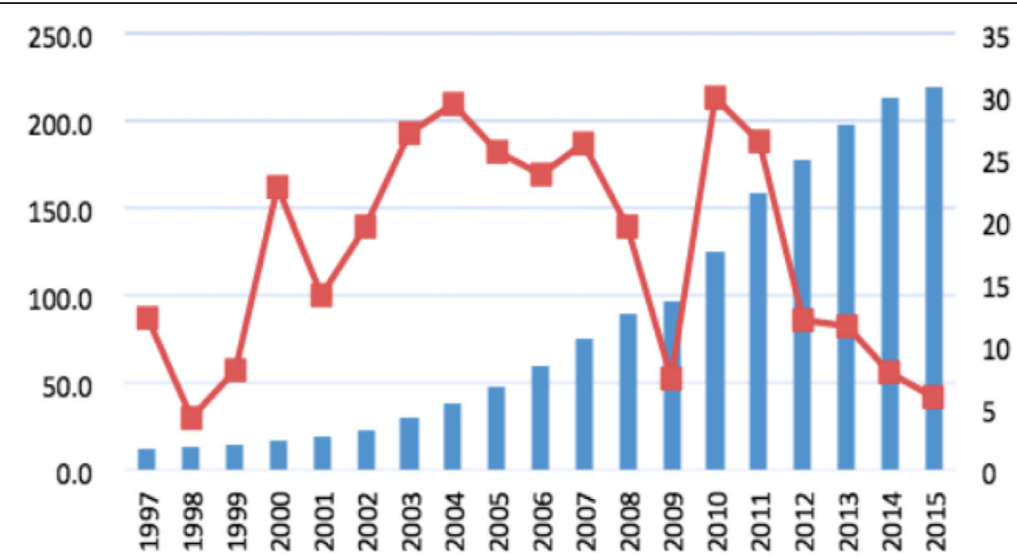

Fig. 1 The year-on-year increase of social logistics from 1997 to 2015. Source: National Statistics Bureau 

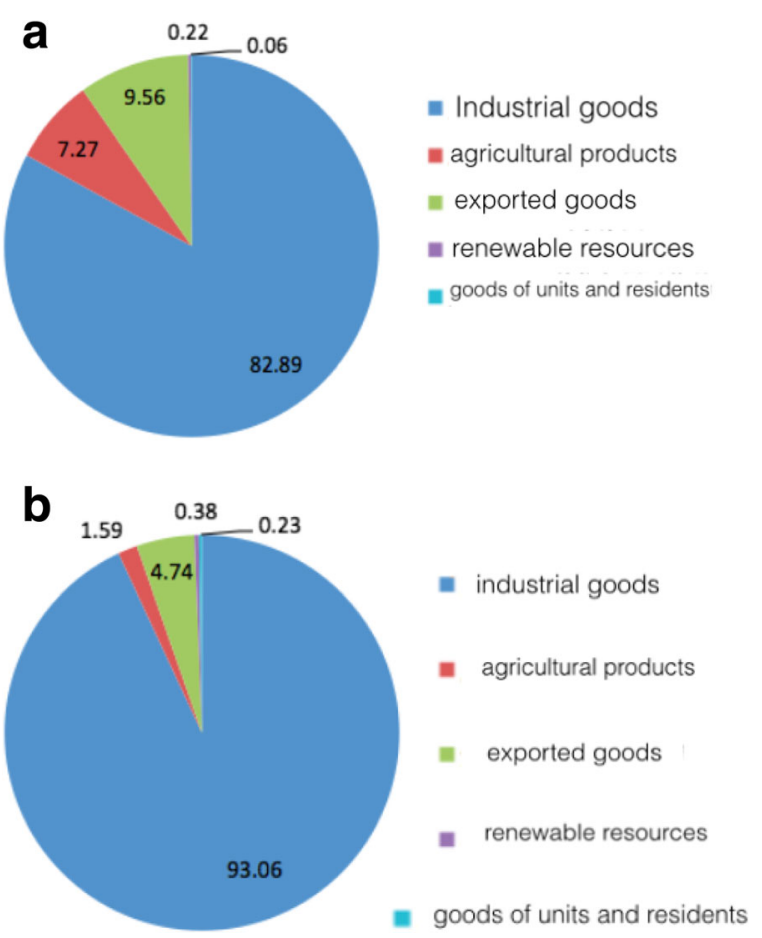

Fig. 2 a The composition of the total social logistic in 1997. b The composition of total social logistics in 2015. Sources: National Bureau of Statistics of China, Bank Consortium Trust Company Limited

From the perspective of social logistics demand coefficient (see Fig. 6), the coefficient of the basic social logistics demand had been rising year by year. This means the scale of logistics required in of creating per unit of GDP is being gradually expanded, and the degree of dependence on logistics industry by the national economy is also on the increase year by year. But starting in 2014, the social logistics demand coefficient began to reduce for the first time in recent 5 years. Year 2015 still witnesses the trend of continuous decrease, showing the scale of logistics required for per unit of GDP has declined. This means that with the transformation of economic growth mode, the optimization of industrial structure, the traditional growth pattern featuring "high

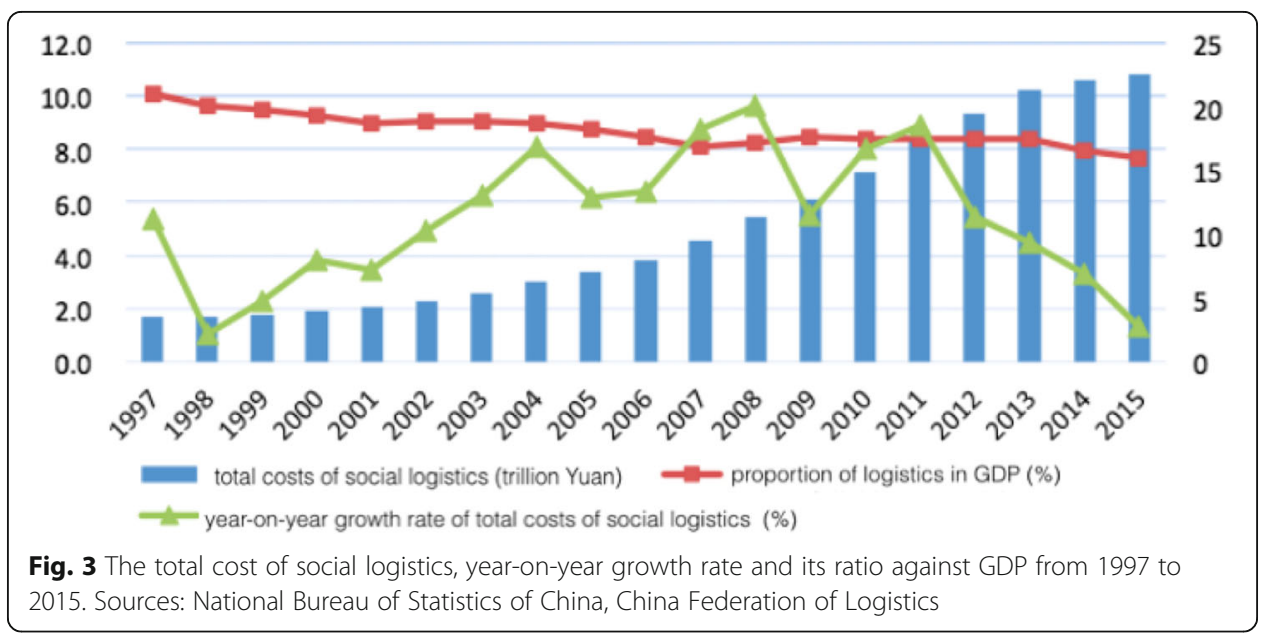




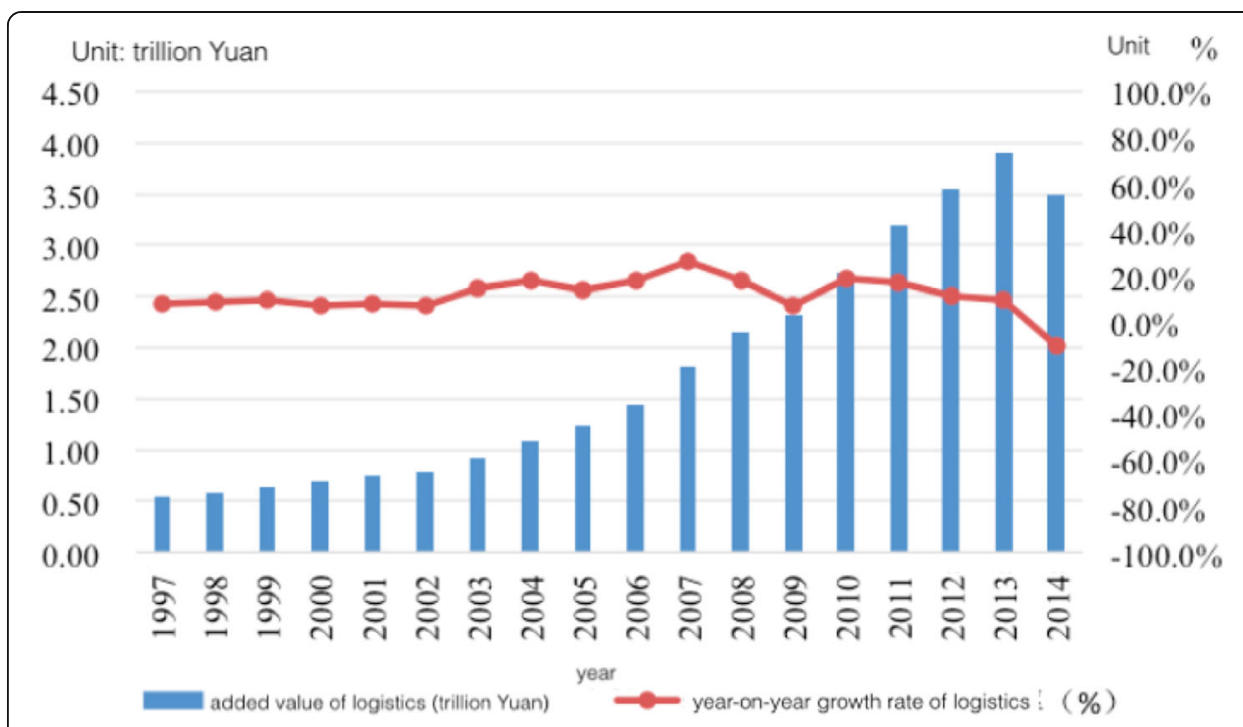

Fig. 4 The added value of the logistics industry and its year-on-year growth rate from 1997 to 2014. Source: National Bureau of Statistics of China

amount of energy consumption and logistics" is changing towards "low energy consumption, high efficiency."

Viewing from the abovementioned indicators, after over 10 years of rapid development, China's logistics industry has slowed down its development speed since 2011 yet its growth rate is higher than GDP growth rate and is amid the range of fast growth. At the same time, the logistics industry is becoming more important in national economy, and the social logistics demand coefficient of social logistics cost is also being reduced year by year, showing its features of being a basic

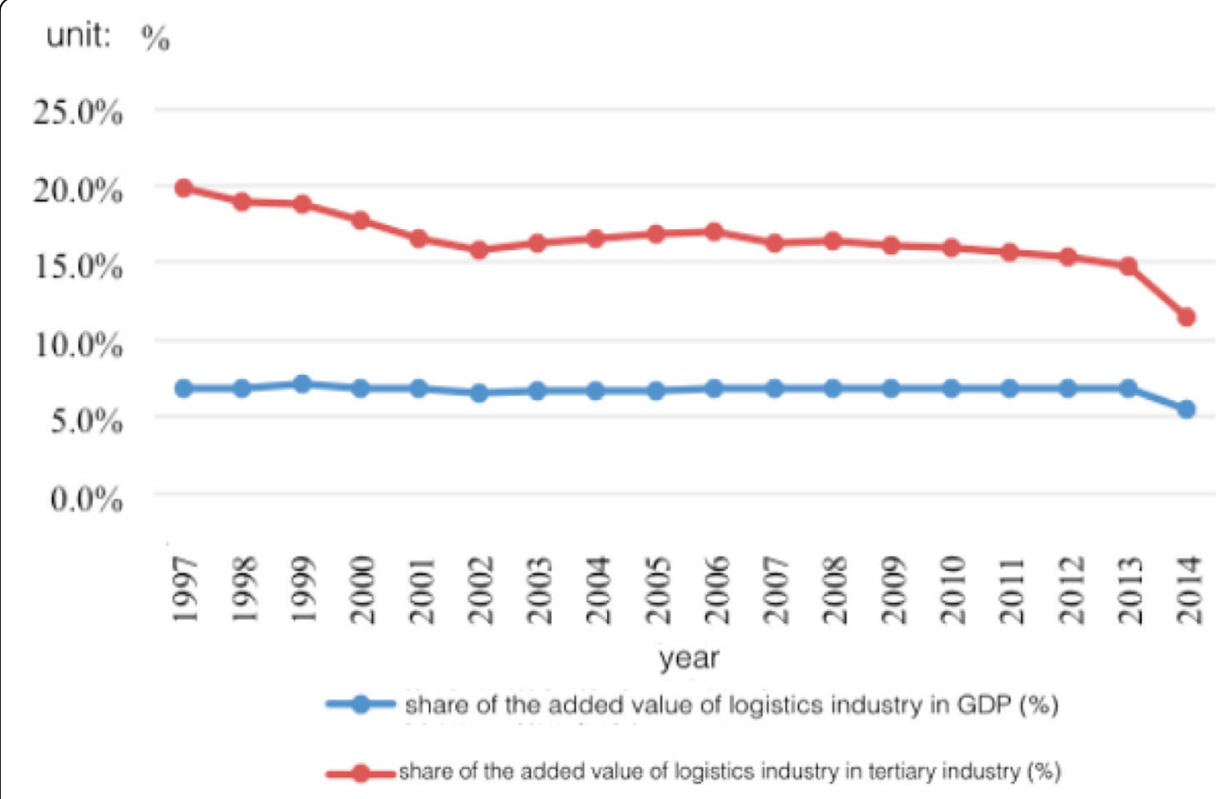

Fig. 5 The proportion of the added value of the logistics industry in GDP and the tertiary industry from 1997 to 2014 respectively. Source: National Bureau of Statistics of China 
service industry are increasingly prominent. But compared with developed economies in Europe and the US and others, China's logistics industry still lags behind them much in both industrial structure and operation efficiency. So far, the logistics industry is still dominated by industrial logistics and logistics service industry takes only a small proportion. However, the proportion taken by logistics service industry in the US, Japan, and other developed countries accounts for over $15 \%$. But with the rapid development of electronic commerce in recent years, the logistics of service industry in our country also has a very broad space for development, with the focus of the logistics industry gradually transferring.

With the rapid development of logistics industry, its characteristics as the basic and strategic industry are growing increasingly significant, and the link between logistics industry and other industries is getting more and more close, so the interaction between the logistics industry and other industries has been a hot topic of concern to scholars. Guanlin Li (2001) was the first one who made a quantitative study on the impact of the logistics industry. Based on the input-output model, he calculated the intermediate demand rate, intermediate input rate, influence coefficient, and induction coefficient of logistics industry and concluded that "development level of China's logistics industry is low, but there is huge space for development. The development of the logistics industry will greatly promote the development of the second industry and the third industry, and promote the overall operation efficiency of the national economy." After that, the input-output model is widely applied into research on the correlation effect of logistics industry (Wang 2007; Shao et al. 2009; Wei et al. 2009; Liang and Wang 2013). However, most of these studies only focus on the driving role and spread effect of logistics industry on other industries, and lack dynamic comparison, which cannot reflect the trend changes. In order to reflect the development trend of logistics and its influence, this article uses the input-output tables of 1997, 2002, 2007, and 2010, taking the changes and developments of logistics industry into consideration and making a dynamic research.

\section{Methods}

Logistics industry, as a newly emerging industry combining dual attributes of being complex and productive, is not a simple superposition of transportation and

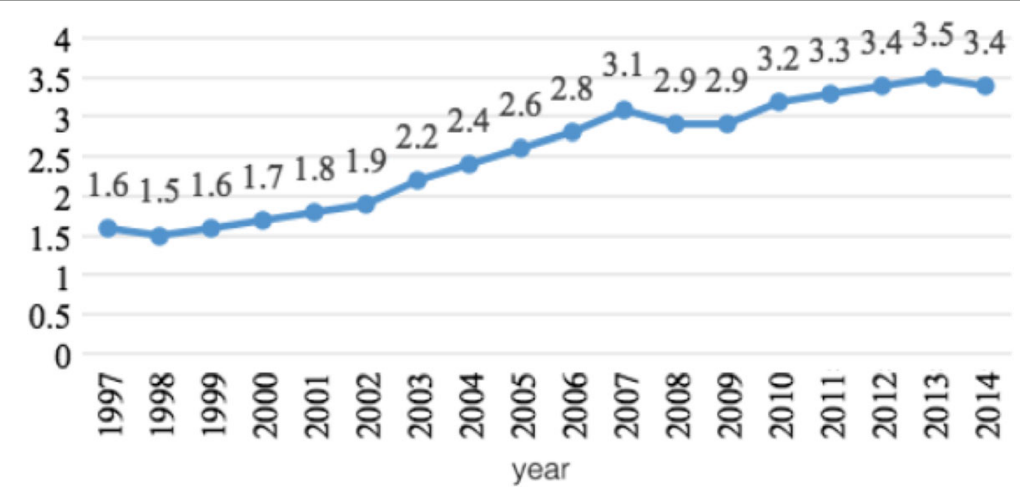

Fig. 6 Social logistics demand coefficient from 1997 to 2014. Source: National Bureau of Statistics of China 
warehousing as well as postal service but also provides service for tertiary industry through optimizing and integrating resources of all aspects. By doing so, the industrial operation efficiency and the quality of economic development have been improved. As there are extensive and close relations between sectors in terms of economy and technology, subtle changes of one industry will exert a certain effect on other industries, which means "involvement." Through the calculation of the input-output table, degree of correlation and involvement among industries can be measured, which will objectively determine the degree of influence of the industry development in related industries and provide a theoretical basis for the formulation and adjustment of industrial policy.

This part mainly introduces the basic structure and internal logical relationship included in the input-output table, the mathematical expression of correlation coefficient and economic implications.

\section{Input-output tables and their basic structure}

Input-output table is also called sectoral balance sheet reflecting the interconnected and balanced proportion relationship between sectors in a certain period. Input-output table can comprehensively and systematically reflect the relation between the input and output of national economic sectors, reveal the economic and technological interdependence and mutual restriction between various sectors in the production process. On the one hand, it reflects the output of all sectors in the national economy and how the output from all sectors was distributed to other sectors for production or to residents and the society for consumption or exports. On the other hand, it also reflects the intermediate input and initial input gained by all sectors in the process of production from other sectors. Input-output table not only reflects the direct economic and technological relationship among various sectors in the process of production but also reveals the indirect relationship among various sectors.

Next, let us look at the basic structure and composition of input-output table specifically (see Table 1).

In the above table, each $d_{i j}$ has double meanings: seen from lines, they represent the demand for the products in the industry of $j$ in the process of production in industry $i$; seen form the columns, they represent the input into the products in industry of $i$ in the production process in industry of $i$. This means that the lines of the table signify the direction of the products and service produced by certain industries; the columns of the table show the composition of the value of the goods or service produced by a certain department of a certain industry.

Balanced relationship in input-output tables

2.1.1.1.Balance relationship at lines of input-output tables The data at the lines of the tables signify the situation of a certain industrial sector providing intermediate products it produces to various sectors including itself. The balanced relationship between lines of the table can be seen as follows:

$$
\sum d_{i j}+f_{i}^{C}+f_{i}^{I}+e_{i}-m_{i}=x_{i}(i, j=1,2 \ldots, n)
$$

Define matrix $D=\left[d_{i j}\right], F^{C}=\left[f_{i}^{C}\right], E=\left[e_{i}\right], M=\left[m_{i}\right], X=\left[x_{i}\right](i, j=1,2 \ldots, n)$. 
Table 1 Basic structure of input-output table

\begin{tabular}{|c|c|c|c|c|c|c|c|c|c|}
\hline & & \multicolumn{3}{|c|}{ Intermediate use } & \multicolumn{3}{|l|}{ Final use } & \multirow[t]{2}{*}{ Import } & \multirow{2}{*}{$\begin{array}{l}\text { Total } \\
\text { output }\end{array}$} \\
\hline & & $\begin{array}{l}\text { Primary } \\
\text { industry }\end{array}$ & $\begin{array}{l}\text { Secondary } \\
\text { industry }\end{array}$ & $\begin{array}{l}\text { Tertiary } \\
\text { industry }\end{array}$ & Consumption & Investment & Export & & \\
\hline & $\begin{array}{l}\text { Primary } \\
\text { industry }\end{array}$ & $d_{11}$ & $d_{12}$ & $d_{13}$ & $F_{1}^{C}$ & $F_{1}^{\prime}$ & $E_{1}$ & $M_{1}$ & $x_{1}$ \\
\hline \multirow[t]{2}{*}{$\begin{array}{l}\text { Intermediate } \\
\text { Input }\end{array}$} & $\begin{array}{l}\text { Secondary } \\
\text { industry }\end{array}$ & $d_{21}$ & $d_{22}$ & $d_{23}$ & $F_{2}^{C}$ & $F_{2}$ & $E_{2}$ & $M_{2}$ & $x_{2}$ \\
\hline & $\begin{array}{l}\text { Tertiary } \\
\text { industry }\end{array}$ & $d_{31}$ & $d_{32}$ & $d_{33}$ & $F_{3}^{C}$ & $F_{3}^{\prime}$ & $E_{3}$ & $M_{3}$ & $x_{3}$ \\
\hline Added value & & $V_{1}$ & $V_{2}$ & $V_{3}$ & & & & & \\
\hline Total input & & $x_{1}$ & $x_{2}$ & $x_{3}$ & & & & & \\
\hline
\end{tabular}

This turns to be the following when indicated in the form of matrix.

$$
D+F^{C}+F^{I}+E-M=X
$$

It means

Intermediate use + final use-exports $=$ total output

2.1.1.2. Balance relationship at columns of input-output tables Data at the columns show the situation of intermediate products bought by all industrial sectors including those of certain industries.

$$
\sum d_{i j}+v_{i}=x_{j}(i, j-1,2, \ldots, n)
$$

This can be shown in the form of matrix:

$$
D+V=X
$$

that is

intermediate input + added value $=$ total input.

2.1.1.3.Balance relationship of the aggregation of input-output tables The total input of an industrial sector equals its total output. Expanding to the whole national economy, this means the total input of all industrial sectors equals the total output.

$$
\sum x_{i}=\sum x_{j}(i, j-1,2, \ldots, n)
$$

Observation at Table 1 can also conclude the intermediate input equals intermediate use.

\section{Major coefficients}

2.1.2.1.Intermediate demand rate Intermediate demand rate $G_{i}$ reflects the amount of total intermediate products (raw materials) required by other industrial sectors of all products of various sectors in national economy. The higher the rate of intermediate demand, the more nature of the raw materials industry is owned by the industrial sectors. On the basis of the intermediate demand rate, the proportion of products of various industrial sectors used for the materials for production 
and consumption will be calculated accurately in order to accurately grasp the position and role of each sector in the national economy.

$$
G_{i}=\sum_{j=1}^{n} d_{i j} / X_{i}(i, j=1,2, \ldots, n)
$$

2.1.2.2. Intermediate input rate Intermediate input rate $F_{j}$ reflects the proportion of raw materials purchased from other industries to satisfy their sectors' own need of producing products of per production unit in the production process of all sectors in national economy. The higher the intermediate rate is, the lower the rate of added value for the industry will be. Industries with high "intermediate rates" mean those industrial sectors with low added values.

$$
F_{j}=\sum_{i=1}^{n} x_{i j} / X_{j}(i, j=1,2, \ldots, n)
$$

2.1.2.3.The direct consumption coefficient The direct consumption coefficient of direct consumption coefficient $a_{i j}$ reveals the economic and technological ties between various sectors of the national economy and measures the interdependence and mutual restriction relationship among sectors. The higher the $a_{i j}$ is, the higher the degree of dependence of sectors in industry $j$ on sector $i$ will be. The lower the $a_{i j}$ is, the lesser the dependence of the sectors of industry $j$ on the sector of $i$ will be.

$$
a_{i j}=\frac{x_{i j}}{X_{j}}(i, j=1,2, \ldots, n)
$$

2.1.2.4.Influence coefficient Influence coefficient $T_{j}$ reflects the degree of involvement of certain industrial sectors on the production demand of all industrial sectors in the national economy when certain industrial sectors in the national economy add one unit for final uses. If influence coefficient is less than 1, the degree of involvement or influence of the industrial sector on other industrial sectors will be less than average level. If the influence coefficient is more than 1 , the degree of involvement or influence of the industrial sector on other industrial sectors will be more than average level.

$$
T_{j}=\sum_{i} b_{i j} /\left(\frac{1}{n} \sum_{i} \sum_{j} b_{i j}\right)(i, j=1,2, \ldots, n)
$$

2.1.2.5.Induction coefficient Induction coefficient $E_{i}$ reflects the degree of involvement of adding one unit for final use for each sector of national economy on demand induction of certain industrial sectors. If the induction coefficient is less than 1 , it can be concluded that the degree of induction of this industrial sector is lower than the average level of all industrial sectors. If the induction coefficient is more than 1 , it can be concluded that the degree of induction of this industrial sector is higher than the average level of all industrial sectors, having stronger capability to restrict national economy but also being driven more by the development of national economy. 


$$
E_{i}=\sum_{j} b_{i j} /\left(\frac{1}{n} \sum_{i} \sum_{j} b_{i j}\right)(i, j=1,2, \ldots, n)
$$

\section{Calculation process and results}

\subsubsection{Calculation process According to Table 1,}

intermediate demand rate can be defined as: $G_{i}=\sum_{j=1}^{n} d_{i j} / X_{i}(i, j=1,2, \ldots, n)$,

intermediate input rate can be defined as: $F_{j}=\sum_{n=1}^{n} x_{i j} / X_{j}(i, j=1,2, \ldots, n)$,

According to formula 2, we can get.

$$
\begin{aligned}
D & =\left[\begin{array}{ccccc}
d_{11} & \cdot & \cdot & \cdot & d_{1 n} \\
\cdot & \cdot & \cdot & \cdot & \cdot \\
\cdot & \cdot & \cdot & \cdot & \cdot \\
\cdot & \cdot & \cdot & \cdot & \cdot \\
d_{n 1} & \cdot & \cdot & \cdot & d_{n n}
\end{array}\right], F^{C}=\left[\begin{array}{c}
f_{1}^{C} \\
\cdot \\
\cdot \\
\cdot \\
f_{n}^{C}
\end{array}\right], F^{I}=\left[\begin{array}{c}
f_{1}^{I} \\
\cdot \\
\cdot \\
\cdot \\
f_{n}^{I}
\end{array}\right], E=\left[\begin{array}{c}
e_{1} \\
\cdot \\
\cdot \\
\cdot \\
e_{n}
\end{array}\right], M=\left[\begin{array}{c}
m_{1} \\
\cdot \\
\cdot \\
\cdot \\
m_{n}
\end{array}\right], X \\
& =\left[\begin{array}{c}
x_{1} \\
\cdot \\
\cdot \\
x_{n}
\end{array}\right]
\end{aligned}
$$

and the following when referring to the definition of $a_{i j}, \bar{m}_{i j}$

$$
X=A X+F^{C}+F^{I}+E-\left[\bar{M}^{A} * A X+\bar{M}^{F} *\left(F^{C}+F^{I}\right)\right]
$$

Among this, we know that

$$
A=\left[\begin{array}{ccccc}
a_{11} & \cdot & \cdot & \cdot & a_{1 n} \\
\cdot & \cdot & \cdot & \cdot & \cdot \\
\cdot & \cdot & \cdot & \cdot & \cdot \\
\cdot & \cdot & \cdot & \cdot & \cdot \\
a_{n 1} & \cdot & \cdot & \cdot & a_{n n}
\end{array}\right], \bar{M}^{A}=\bar{M}^{F}=\left[\begin{array}{ccccc}
m_{1} & 0 & \cdot & \cdot & 0 \\
0 & m_{2} & \cdot & \cdot & 0 \\
0 & 0 & \cdot & 0 & 0 \\
0 & 0 & 0 & \cdot & 0 \\
0 & 0 & \cdot & \cdot & m_{n}
\end{array}\right]
$$

This can be changed after calculation as follows:

$$
X=\left[I-\left(I-\bar{M}^{\mathrm{A}}\right) A\right]^{-1} *\left[\left(I-\bar{M}^{F}\right)\left(F^{C}+F^{I}\right)+E\right]=B^{*} G
$$

From the above, we can get:

$$
B=\left[I-\left(I-\bar{M}^{A}\right) A\right]^{-1}, G=\left[\left(I-\bar{M}^{F}\right)\left(F^{C}+F^{I}\right)+E\right]
$$

$b_{i j}$ is the element.

Influence coefficient can be defined as: $T_{j}=\sum_{\mathrm{i}} b_{i j} /\left(\frac{1}{n} \sum_{\mathrm{i}} \sum_{\mathrm{j}} b_{i j}\right)(i, j=1,2, \ldots, n)$

Induction coefficient can be defined as: $E_{i}=\sum_{\mathrm{j}} b_{i j} /\left(\frac{1}{n} \sum_{\mathrm{i}} \sum_{\mathrm{j}} b_{i j}\right)(i, j=1,2, \ldots, n)$

We will decompose the result of $X$ further into the following. 


$$
\begin{aligned}
X & =[I-A]^{-1} *\left(I-\bar{M}^{F}\right) * F^{C}+\left[I-\left(I-\bar{M}^{A}\right) A\right]^{-1} *\left(I-\bar{M}^{F}\right) * F^{I}+\left[I-\left(I-\bar{M}^{A}\right) A\right]^{-1} * E \\
& =B F^{D C}+B F^{D I}+B E
\end{aligned}
$$

This formula has shown the relationship between $X$ and other parts.

2.1.3.2. Results of calculation Transportation and warehousing, postal service will take the results summary to Table 2 .

Investigations into the changes of coefficients of transportation and warehousing series (see Fig. 7). The intermediate input rate, intermediate demand rate, and influence coefficient of transportation and warehousing industry and induction coefficient all have increased compared with the number in 2007.

Investigations into the variations of coefficients in post industry (see Fig. 8) show that the intermediate input rate, intermediate demand rate and influence coefficient of post industry have risen compared with the year 2007, while the coefficient of industrial induction has fallen.

\section{Analysis into the characteristics of the correlation within logistics industry Analysis into the intermediate demand and intermediate input of logistics industry}

2.2.1.1. Analysis into the total amount and structure Generally speaking, the national economy is divided by three sectors. From this perspective, the transportation and warehousing as well as the postal service belong to the third industry. With the speeding up of industrialization process and the rising service sector, the focus of the development of national economy is gradually shifting to the third industry, which can be proved by Fig. 9. Therefore, in order to explain the relationship between transportation and warehousing as well as the postal service and other industrial sectors (i.e., the logistics industry referred in this article), we divide the transportation industry and warehousing industry as well as post industry (referred as logistics industry in this article) from the third industry and list it separately. It can be found from Fig. 9 that during the 17 years from 1997 to 2014, the proportion of the added value of the primary industry in GDP is increasingly reduced; the second industry has basically presented a trend of inverted v, meaning the figure tends to be stable since 2006; the third industry

\begin{tabular}{|c|c|c|c|c|c|}
\hline Year & Industrial sector & $\begin{array}{l}\text { Intermediate } \\
\text { input rate }\end{array}$ & $\begin{array}{l}\text { Intermediate } \\
\text { demand rate }\end{array}$ & $\begin{array}{l}\text { Influence } \\
\text { coefficient }\end{array}$ & $\begin{array}{l}\text { Induction } \\
\text { coefficient }\end{array}$ \\
\hline \multirow[t]{2}{*}{1997} & \multirow{2}{*}{$\begin{array}{l}\text { Transportation industry, warehouse industry, } \\
\text { and post industry }\end{array}$} & 0.4343 & 0.8500 & 0.8316 & 1.0922 \\
\hline & & 0.4253 & 0.8035 & 0.8615 & 0.6826 \\
\hline \multirow[t]{2}{*}{2002} & \multirow{2}{*}{$\begin{array}{l}\text { Transportation industry, warehouse industry, } \\
\text { and post industry }\end{array}$} & 0.5160 & 0.7525 & 0.9351 & 1.9163 \\
\hline & & 0.6005 & 0.6135 & 1.0459 & 0.4440 \\
\hline \multirow[t]{2}{*}{2007} & \multirow{2}{*}{$\begin{array}{l}\text { Transportation industry, warehouse industry, } \\
\text { and post industry }\end{array}$} & 0.5387 & 0.7721 & 0.8844 & 1.4680 \\
\hline & & 0.5095 & 0.8842 & 0.8555 & 0.3818 \\
\hline \multirow[t]{2}{*}{2010} & \multirow{2}{*}{$\begin{array}{l}\text { Transportation industry, warehouse industry, } \\
\text { and post industry }\end{array}$} & 0.6053 & 0.8978 & 0.9267 & 1.6033 \\
\hline & & 0.6146 & 0.9275 & 0.9321 & 0.3783 \\
\hline
\end{tabular}

Table 2 Coefficient of logistics industry in input-output table

Data source is gained by sorting data from National Bureau of Statistics of China and the websites of China Federation of Logistics 


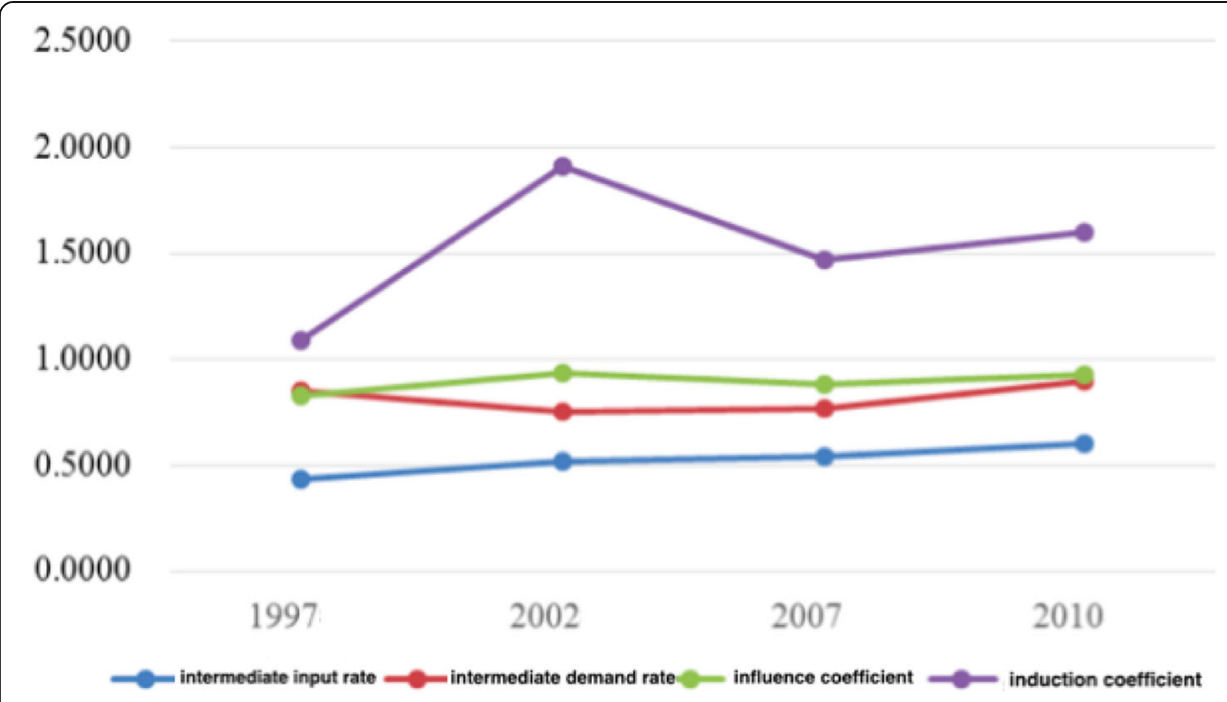

Fig. 7 Variations of the coefficients in transportation and warehousing industries. Source: National Bureau of Statistics of China

(excluding the logistics industry and this is true to all the following mention) has risen continuously in recent years and has exceeded the proportion of the second industry in GDP in 2014; logistics industry, since 1997, has remained at the level of 5\% of GDP. But it has dropped slowly from $6.23 \%$ in 2001 to $4.43 \%$ in 2013 and rebounds slightly in 2014 .

Comprehensively speaking, the logistics industry is currently facing the challenge of transformation, which means that in the next few years the dominant role of industrial logistics in China's logistics industry will gradually shift to service-oriented logistics. The express delivery industry, in particular, has maintained rapid growth faster than

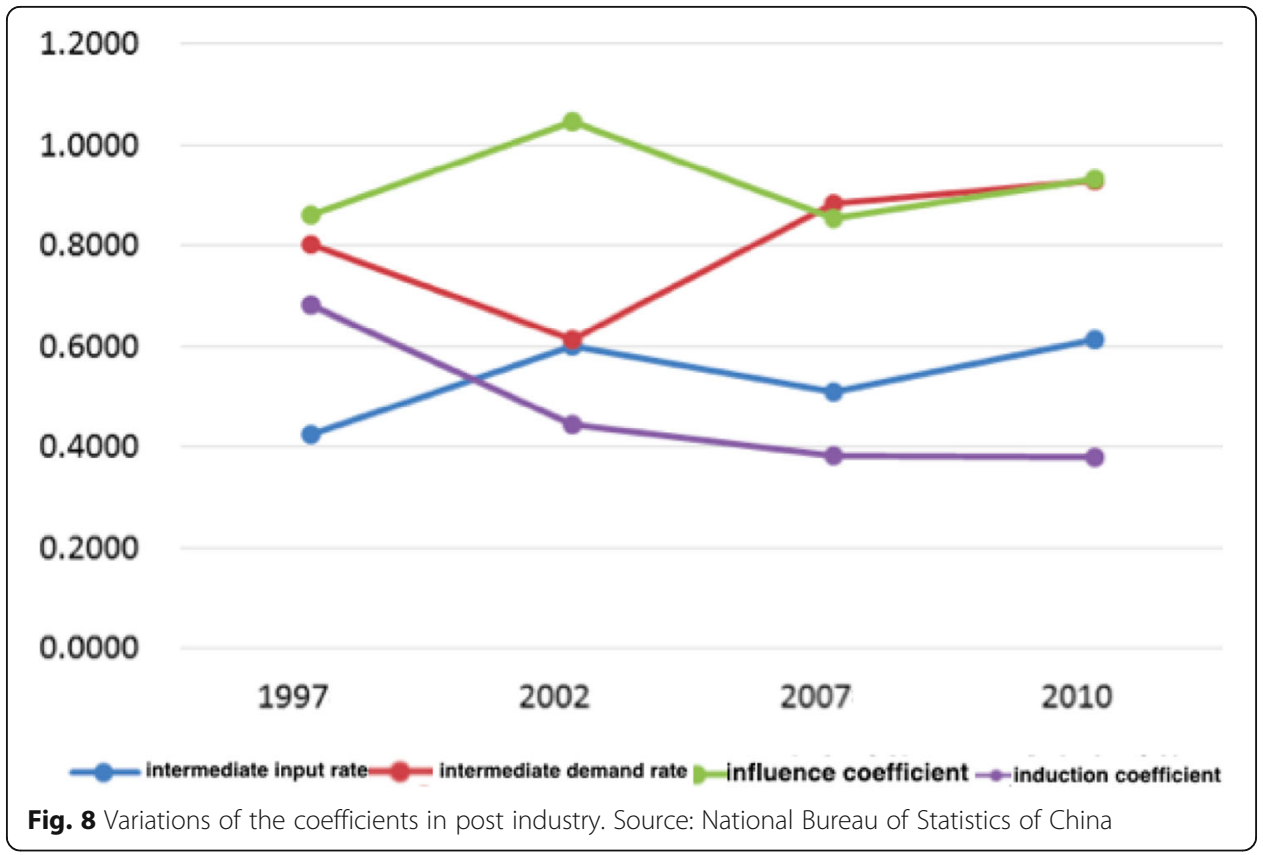


double digits for consecutive 3 years since 2011 and become a new growth point in the development of logistics industry.

2.2.1.2. Analysis into Intermediate demand rate and Intermediate input rate According to the table for the fourth period of input and output in years of 1997, 2002, 2007, and 2010, we can fix the lines for transportation industry, warehousing industry, and post industry and then sum the figures for each column. Finally, the total input is divided and the intermediate rate $G_{i}$ can be gained.

Intermediate demand rates of transportation industry, warehouse industry, and post industry can be shown in Table 3 .

Figure 10 shows the variations of intermediate demand rates in transportation and warehousing, postal service throughout the years. Through observation, it can be found that since 1997, the intermediate rates of transportation, warehousing, and post industry have risen with fluctuations, showing that the whole logistics industry is increasingly important in the whole national economy. As the higher the intermediate rates of the products of a certain sector are, the more features of intermediate products are owned by a certain industrial sector and the more driving force will be put into national economy. By 2010, the intermediate demand rates of transportation, warehousing, and the postal service all exceed 0.85 , implying that the products of logistics industry are invested into sectors of national economy in the form of intermediate products. Meanwhile, it also can be confirmed that logistics industry provides support to the development of other industries and the national economic growth and belongs to the service industry.

According to the input-output table for the fourth period, we can fix the columns of transportation industry, warehouse industry, and post industry, then sum the figure of each line and finally divide the total input to get the intermediate rate $F_{j}$ (see formula 7).

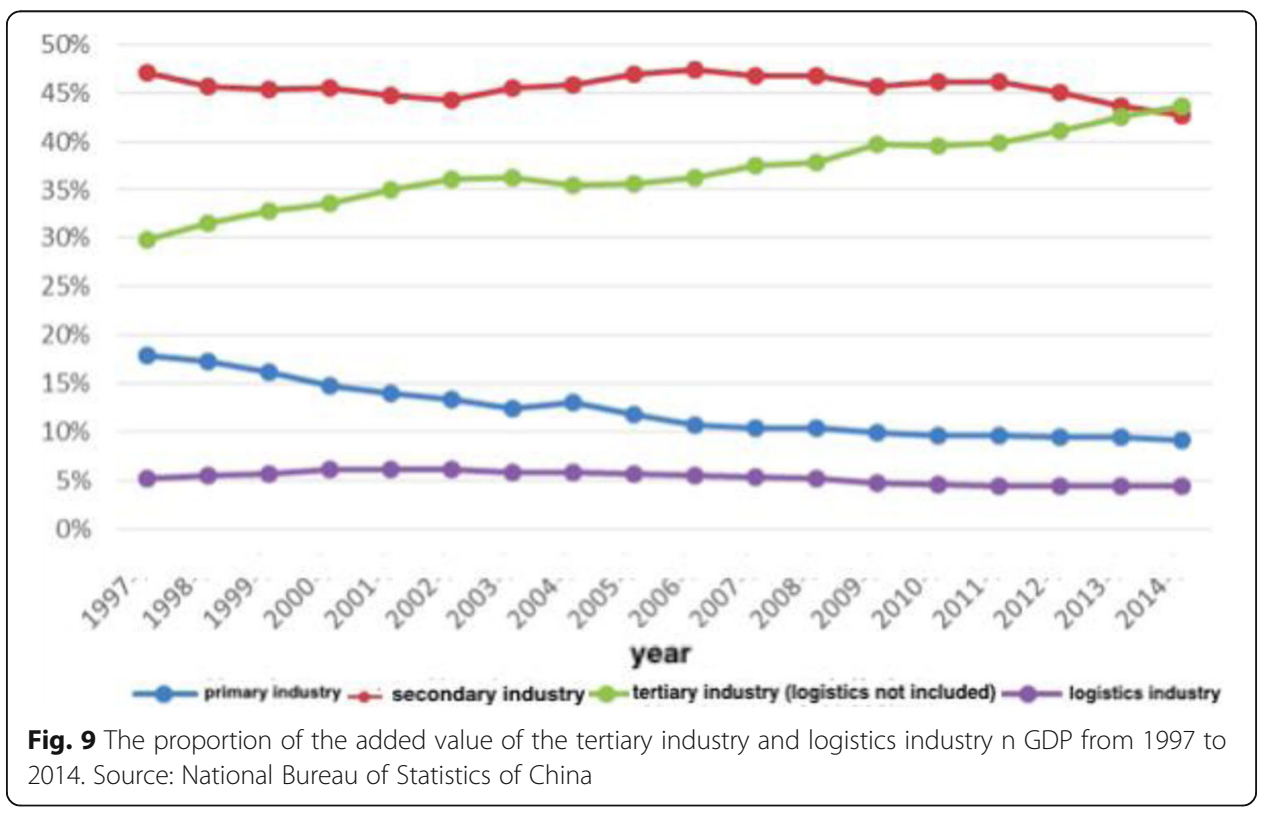


The input rates of transportation industry, warehouse industry, and post industry can be seen in Table 4:

Figure 11 shows the variations of the intermediate rates of transportation industry and warehousing industry and post industry. Generally speaking, the intermediate rate takes 0.5 as the dividing line. The intermediate rates above 0.5 belong to the category of industries with "low added value and strong driving force", while those below 0.5 belong to the category of industries with "high added value and weak driving force." Investigation into the trend in industries like transportation, warehousing, and post industry since 1997 can allow us to conclude that logistics industry in 1997 belong to those with "high added value and weak driving force"; since 2002, the intermediate input rates of the above industries are all above 0.5 and reach 0.6 in 2010, which means the logistics industry had gradually turned into industries with "low added value and strong driving force." This shows the logistics industry's features as a fundamental service industry is increasingly prominent and exerting an increasingly strong driving force on other industrial departments in national economy.

\section{Analysis into direct consumption coefficients}

From a statistical standpoint, there is some discrepancy on the classification of documentation and statistical caliber throughout the years within the calculation period for this report. The calculation result shows that there were 40 sectors in 1997, 42 in 2002, and 41 in 2010. Among these figures, there are some that are involved with the variations concerning the logistics industry that refer to the division of the post industry into post industry, transmission industry, computer service, and software industry; transportation of goods, warehousing, and passenger transportation are merged once again into transportation and warehousing industry. Although there are some changes on classification method and the statistical caliber, the overall development trend of the logistics industry has not been affected by changes on classification and statistical caliber. Thus, we should now overlook such change. The following are the direct consumption coefficients of each industry.

2.2.2.1. Direct consumption coefficients The calculation of direct consumption coefficient $a_{i j}$ can be seen formula 8 .

Direct consumption coefficient of logistics industry against the departments of various sectors and the direct consumption coefficient of various sectors against logistics industry can be calculated separately and then be ordered. This thesis analyzes the top five industries in the rank of direct consumption coefficients. The main reason for doing so is the correlation degree of the top five industries with

Table 3 Intermediate demand rates of transportation industry, warehouse industry, and post industry

\begin{tabular}{lll}
\hline Year & $\begin{array}{l}\text { Transportation industry, warehouse } \\
\text { industry, and post industry }\end{array}$ & Post industry \\
\hline 1997 & 0.8500 & 0.8035 \\
2002 & 0.7525 & 0.6135 \\
2007 & 0.7721 & 0.8842 \\
2010 & 0.8978 & 0.9275 \\
\hline
\end{tabular}

Source: National Bureau of Statistics of China 


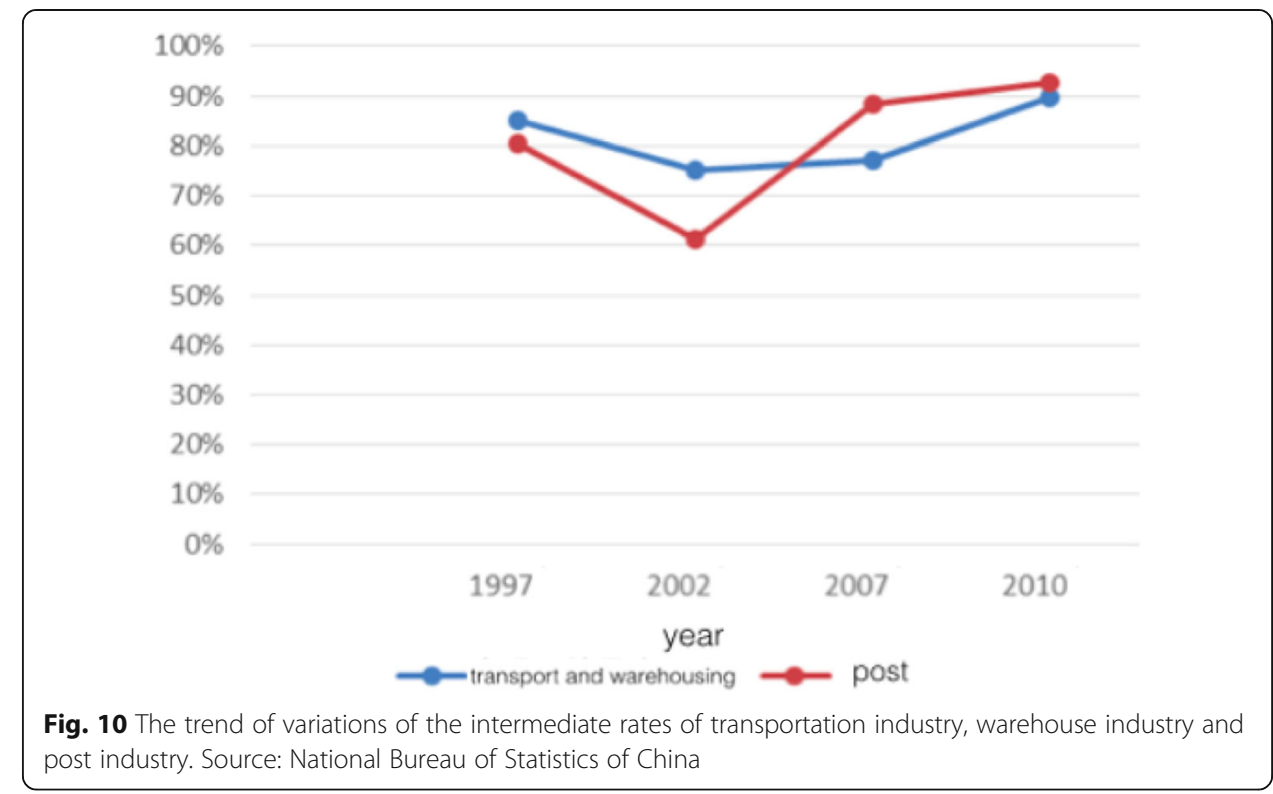

transportation, warehousing, and post industry is the biggest and we can observe the conglomerations of the primary industry, secondary industry, and tertiary industry of every segmental sector in the list of top five.

\subsubsection{The analysis into the direct consumption coefficients of logistics industry} against various sectors It can be seen from Table 5 that during the documentation period of the four input-output tables, the direct consumption coefficient of logistics industry against various sectors has undergone a structural shift which means a significant rise of the third industry. Concretely, industries like transportation and warehousing have exerted few impact on the changing ranks of direct consumption coefficients. In 1997, all industrial sectors among the top five list, except for themselves, belong to the secondary industry. But since 2002, the top five list had witnessed the appearance of the third industry-the financial sector. The rank of oil processing and coking industry, transportation equipment manufacturing, and general equipment manufacturing industry ranking are basically stable, and all of them are the upstream industries of the transportation and warehousing industry, which means they provide production materials and tools for transportation and warehousing industry. So the transportation industry and warehousing industry depend on the development of these industries. On the other hand, the development of transportation and warehousing industry will also greatly promote the development of these industries. In addition, development of transportation and warehousing industry is also dependent on their own development.

From the perspective of postal service, the ranking of post industry against various industrial sectors throughout the four documentation periods is quite stable. Transportation and warehousing, transportation equipment manufacturing, construction, and wholesale and retail basically have been comfortably in the top five. Since 2007, the postal service is highly dependent on the transportation and warehousing and transportation equipment manufacturing industries. 
Table 4 Intermediate input rates of transportation industry, warehouse industry, and post industry

\begin{tabular}{lll}
\hline Year & $\begin{array}{l}\text { Transportation industry, warehouse } \\
\text { industry, and post industry }\end{array}$ & Post industry \\
\hline 1997 & 0.4343 & 0.4253 \\
2002 & 0.5160 & 0.6005 \\
2007 & 0.5387 & 0.5095 \\
2010 & 0.6053 & 0.6146 \\
\hline
\end{tabular}

Source: National Bureau of Statistics of China

In general, the focus of China's logistics industry is gradually shifting from the industrial logistics to logistics service industry. But judging from all the rankings, currently China's logistics industry is still dominated by industrial logistics. It is worth mentioning that the ranking of direct consumption coefficients of transportation and warehousing industries on industries like agriculture, forestry, husbandry, and fishing has risen from 26th in 1997 to 6th in 2010. This also reflects from one side that at present our country's agricultural product logistics is developing rapidly, becoming a new growth point of the logistics industry.

2.2.2.3.Analysis into the direct consumption coefficients of industrial sectors against logistics industry From Table 6, the changes on the ranking of various industrial sectors in the four input-output tables throughout the period of documentation period can be found. Transportation and warehousing industry, non-metallic mining and mining industry, and the construction industry has been the greater consumption of transportation and warehousing industry; the postal service is occupying the first since 2007. This shows that the industry is in the downstream of transportation and warehousing industry and needs to consume large amounts of transportation and warehousing products. Integrated in the top 10, lease and commodity services since 2007, and integrated technology services, wholesale and retail, broke past the second industry sector the situation to unify the whole country; the third sector began a large number of demand of transportation and warehousing of products.

From the perspective of the postal service, since 1997, the postal service is highly dependent on its own development. Comprehensively considering the direct consumption coefficient of all the industrial sectors on the postal service, the top ten sectors

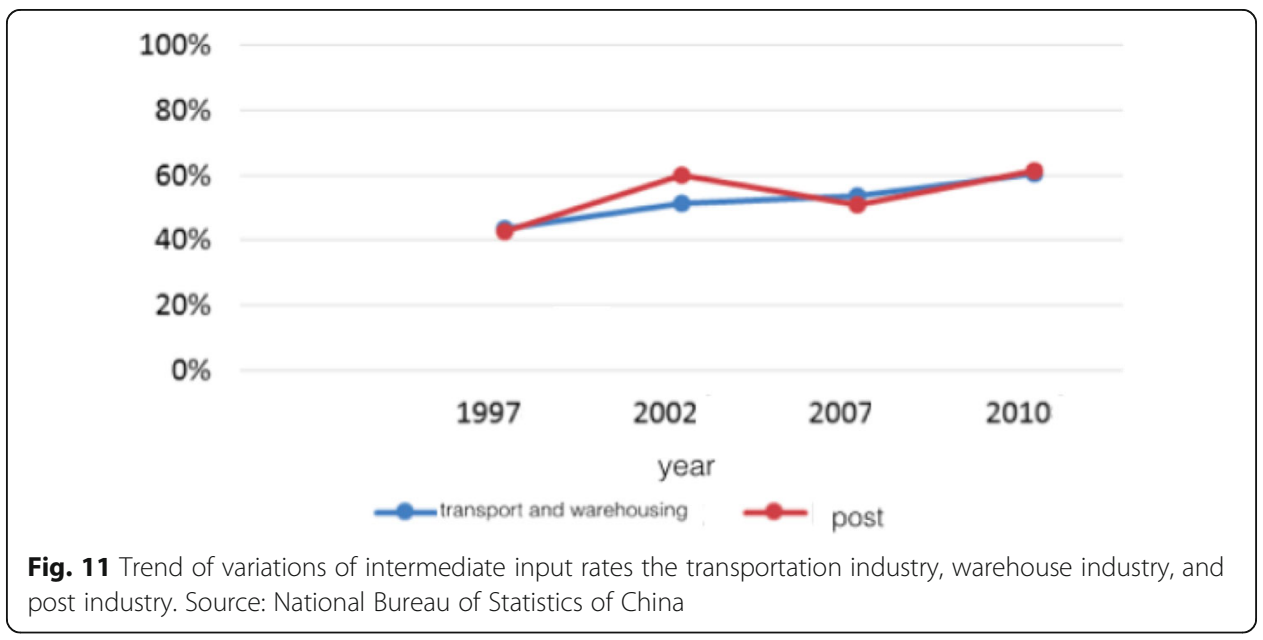




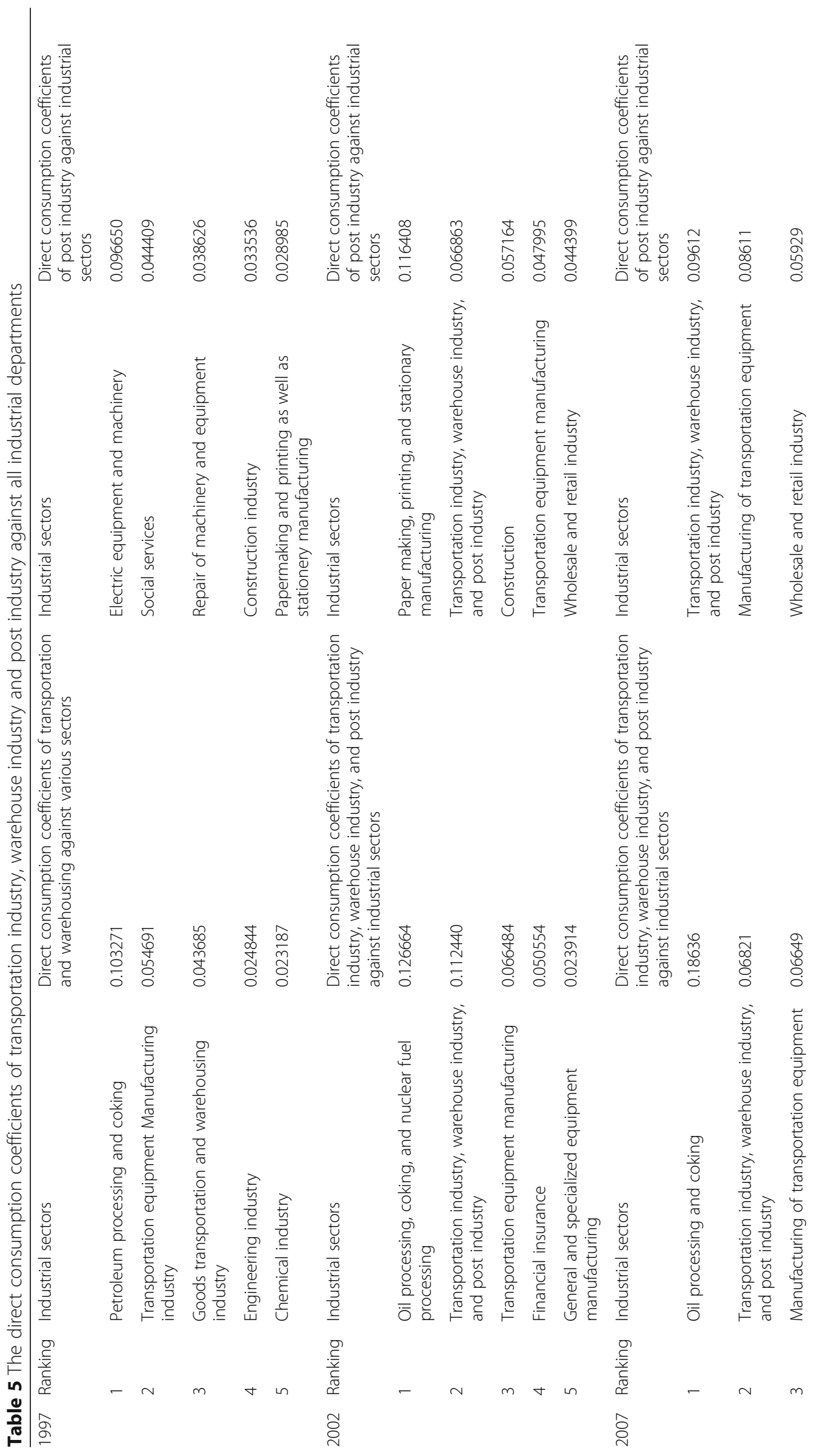




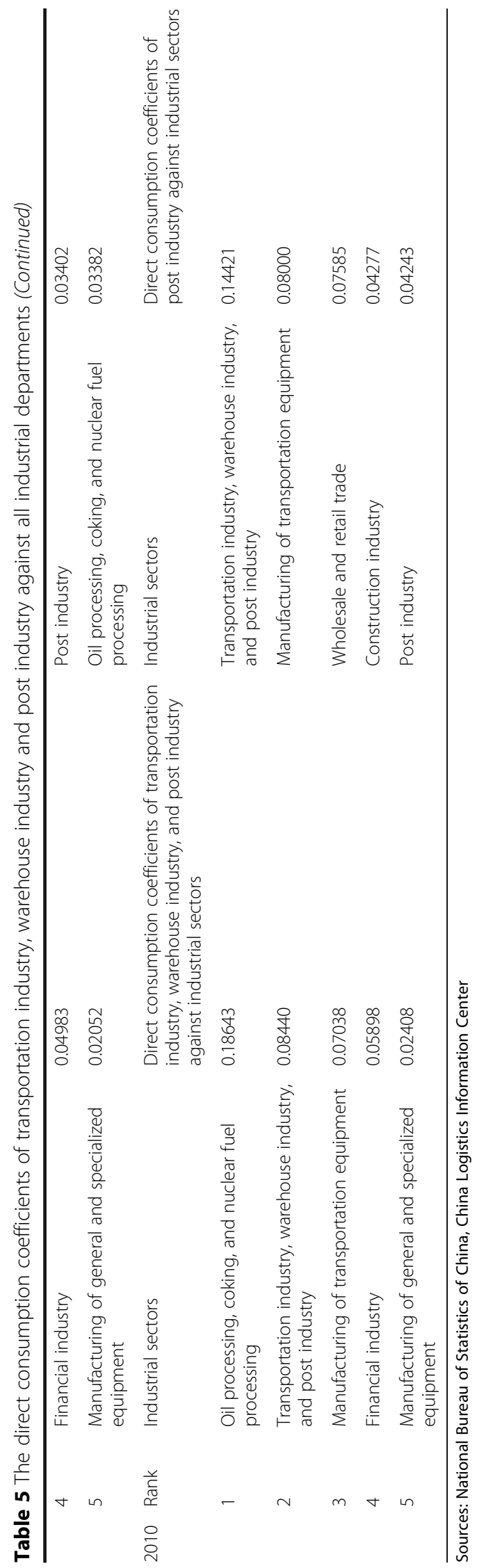


were almost occupied by the tertiary industry departments, showing that the tertiary industry is highly dependent on the development of the postal service industry. The continuous development and improvement of the postal industry can greatly promote the development of the tertiary industry such as public management and social organization, leasing and business services, finance industry, research and experimental development industry, and ensure the quality of service of the tertiary industry.

Integrated logistics of each industrial sector and industry sector of the direct consumption coefficient of the logistics industry, logistics industry after 2002 belongs to the "low value-added, motivating strong" sector, the leading role of national economic development is mainly to provide complete integration of the supply chain upstream and downstream enterprises, and the optimization of circulation enterprises offline channels as the increasing proportion of tertiary industry in the national economy; the third industry direct consumption of the logistics industry will be more and more big. During the period of much starker choices-and graver consequences-in, logistics industry will be dominated by industrial logistics gradually transition to the logistics service industry as the leading factor, which not only conforms to the developing direction of the national economy but also to promote economic restructuring.

\section{Analysis into the features of Logistics Industry's involvement Analysis into influence coefficients}

The calculation formula of influence coefficient $T_{j}$ is seen in formula 9.

When investigating calculation results comprehensively, it can be found that sectors whose influence coefficients are less than 1 are mostly concentrated in the primary industry and tertiary industry as well as a few sectors of the second industry. The sectors of the secondary industry whose influence coefficient are less than 1 are basically mining and separating industry, and energy industry with a prominent nature of raw materials in production industry, belonging to the upstream sector of the industry chain, thus exerting smaller effect on other industrial sectors. The vast majority of sectors whose influence coefficients are more than 1 are mainly concentrated on the secondary industry and tertiary industry, among which the secondary industry whose influence coefficient is higher than 1 is basically equipment manufacturing industry which boasts high technological content and has been fully developed with relative great influence and radial force. And the tertiary industry sectors whose influence coefficients higher than 1 are mainly industries like health, social security and social welfare industry, researches and experiments industry, and leasing and business services.

Observation of the Table 7 can enable us to conclude that in 1997 and 2002, the general ranking of the major industries within logistics increased slightly. But in 2007, the figure returned to the level of 2002 once again, a relative great rise compared with the figure of 1997.

Comprehensive comparison with other sectors shows that the influence coefficient of the whole logistics industry ranks at middle and low levels of over 40 industrial sectors. Besides, except for 2002 when the influence coefficient of postal service is more than 1 , the influence coefficients of other times are all less than 1, showing that although the 


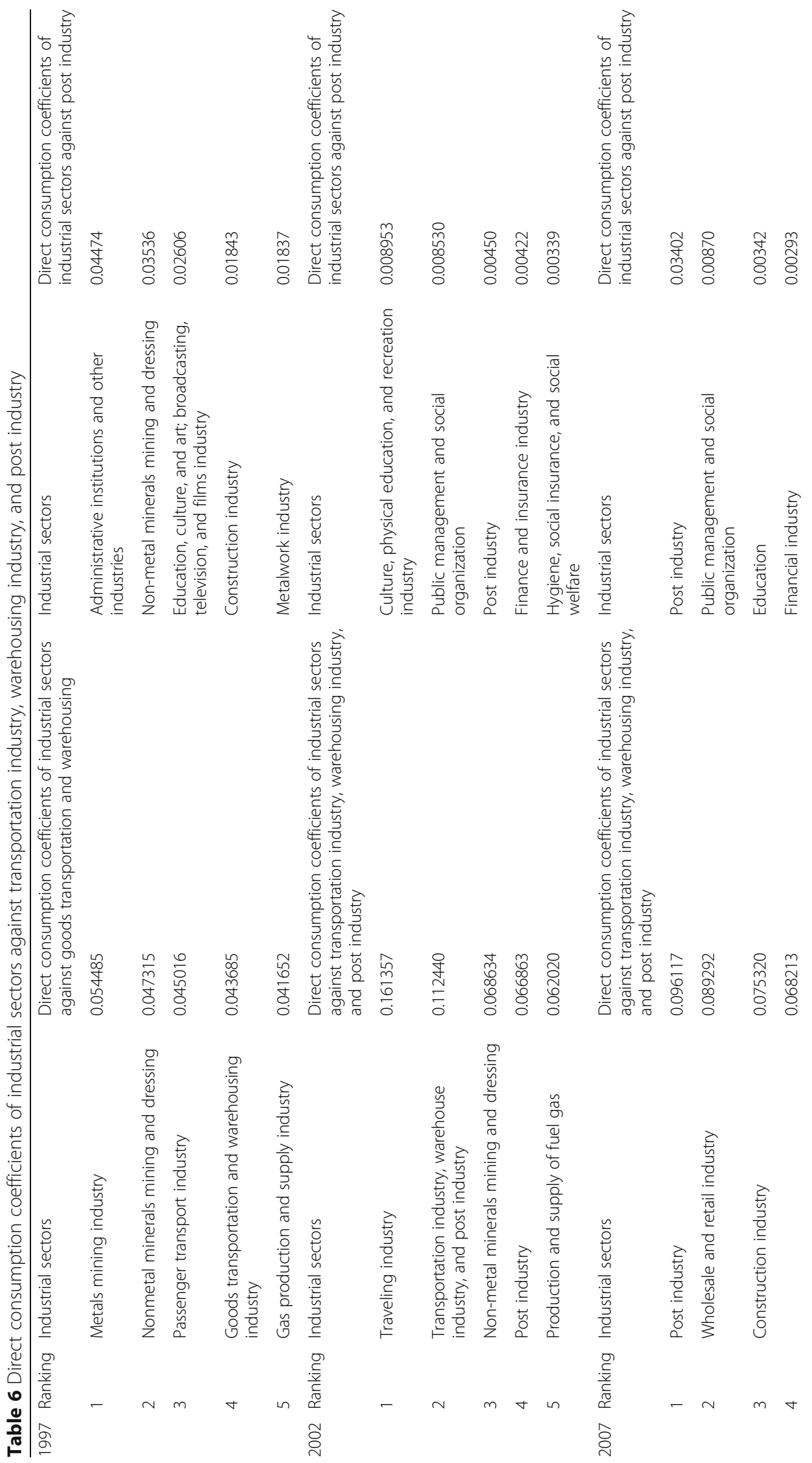




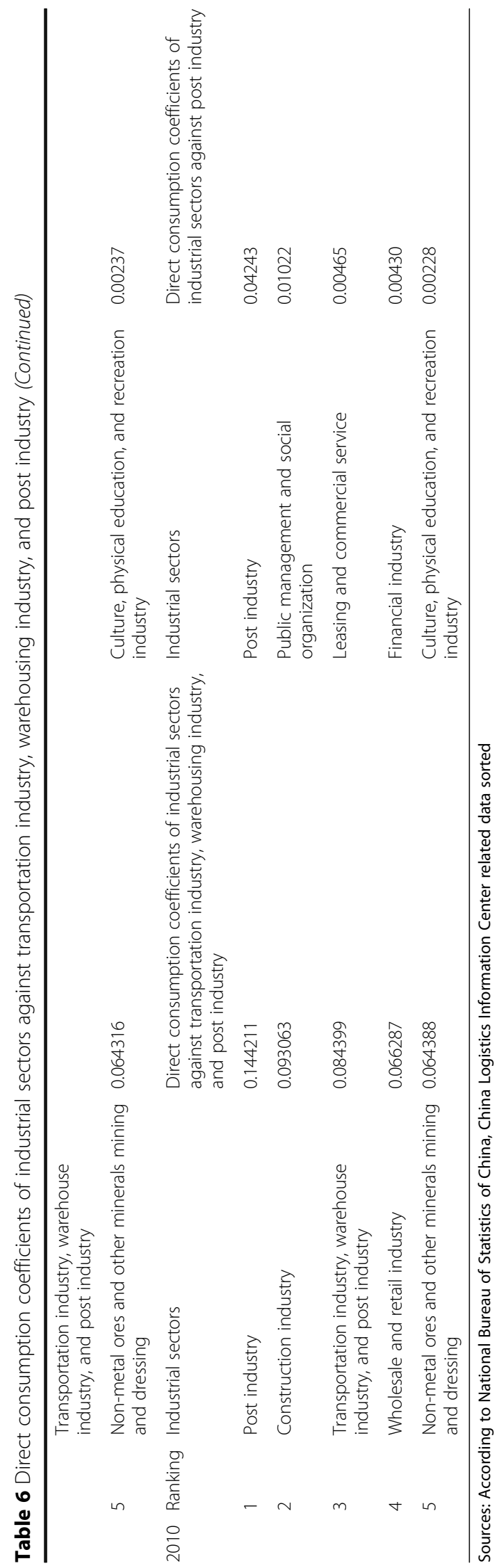


logistics industry in our country has made some progress in the documentation periods of the four input-output tables they have exerted impact less than the average on other industrial sectors. This shows our country's logistics industry has been in a stage of development with broad development space.

\section{Analysis into induction coefficient}

The calculation formula for induction coefficient $E_{i}$ can be seen in formula 10,and their specific calculation result can be seen in Table 4. Comprehensively, inspection on the calculation results conclude that the industrial sectors whose induction coefficient are less than 1 are basically at several sectors of the third industry and the second industry. Sectors with induction coefficient smaller than 1 basically belong to the category of basic, traditional processing, and manufacturing industry, and their products are attached with some nature of the intermediate products. In particular, the induction coefficients of chemical industry, metal smelting, and rolling processing industry has reached to a level of industry of the production and supply of electricity and heat to achieve the sector average of 2 to 3 times of the sector's average, indicating that these sectors have played a major role in promoting the development of national economy. But in the process of the development of national economy, these sectors are always those with the largest pressure on demand. Thus, once their development is lagged behind, they will be the "bottleneck" restricting the development of national economy.

Inspection into Table 8 can allows us to find that in comparison to 1997 when the induction coefficient of the transportation and warehousing industry has been significantly enhanced, figures have been stable since 2002 at the ranking of top 10 . In addition, all of their coefficients were greater than 1. Judging comprehensively from the induction degree of all sectors, induction coefficients of transportation and warehousing industry are relatively large, far higher than the average level. This indicates that the demand for transportation and warehousing industry by the national economy is quite huge. However, the ranking of postal service has dropped since 1997 at a rather low level. And its induction coefficient was less than 1 at 0.5 basically. This shows that the induction degree of post industry is far lower than the average level. This means that the position of postal service has dropped in national economic development at present.

\section{Analysis into cross correlation}

According to the standard of division mentioned in above, we divide "influence coefficient-induction coefficient" into four quadrants by taking the average value of

Table 7 Influence coefficient and their ranking of transportation industry, warehouse industry, and post industry

\begin{tabular}{llllll}
\hline Year & \multicolumn{2}{l}{ Transportation industry, warehouse industry, and post industry } & & \multicolumn{2}{l}{ Post industry } \\
\cline { 2 - 3 } & Ranking & Influence coefficient & & Ranking & Influence coefficient \\
\hline 1997 & 34 & 0.831571 & 33 & 0.861454 \\
2002 & 27 & 0.935070 & 19 & 1.045899 \\
2007 & 30 & 0.884366 & 31 & 0.855527 \\
2010 & 26 & 0.926670 & 25 & 0.932087 \\
\hline
\end{tabular}

Source: National Bureau of Statistics of China 
1.0 for all industrial sectors as division line. The characteristics of association among industries like transportation, warehousing, and postal service industry can be more visualized. Because the recent input-output table was made in 2010, situation reflected in this table is more close to the current development circumstance of our country's logistics industry longitudinally and the degree of correlation between logistics industry and other industries can be reflected more clearly. Thus, we take the input-output table in 2010, for example, to draw a chart of "Influence coefficients-Induction coefficients of each industrial sector" shown in Fig. 12.

In the first quadrant are those industrial sectors whose "influence coefficient is less than 1 and induction coefficient is greater than 1." These sectors have weaker influence but stronger restrictive capability. Transportation and warehousing industries are located in the first quadrant, showing its characteristic of being "bottlenecks". In the first quadrant II are those industrial sectors whose "influence coefficient and induction coefficient were greater than 1" with dual attributes of strong capacity and restrictive capability. These industrial sectors are the backbones in national economic development process, being both the main provider and consumer of intermediate products at the same time. Thus, they have strong ability in influence and restriction. In the quadrant III are industrial sectors whose "influence coefficient and influence coefficient are less than 1." They are mainly sectors of the third sector, exerting rather weak influence and restriction on the development of national economy. In the first quadrant IV are those with "influence coefficient greater than 1 and induction coefficient less than 1", a strong ability of influence but weaker restriction.

Combining with the results in input-output table in 2010 and taking the direct consumption coefficients of transportation and warehousing industry, for example, it can be seen from the top five that the direct consumption coefficients of transportation and warehousing against oil processing and coking, nuclear fuel processing industry, transportation equipment manufacturing industry, general motors, and special equipment manufacturing industry are very large. And these sectors are located in the quadrant II with dual natures of strong influence and strong restriction ability as upstream industries of the transportation and warehousing industry. Transportation and warehousing industry are not only highly dependent on the development of these industries but also constrained by the strong impact and strong restriction exerted by these sectors at the same time. Given that the industries associated with China's transportation and warehousing are mainly focused on the second industry, we should coordinate the transportation and warehousing industry in order to adapt themselves to the second industry, seize

Table 8 Induction coefficients and their ranking in transportation industry, warehouse industry, and post industry and post industry

\begin{tabular}{|c|c|c|c|c|}
\hline \multirow[t]{2}{*}{ Year } & \multicolumn{2}{|c|}{ Transportation industry, warehouse industry, and post industry } & \multicolumn{2}{|c|}{ Post industry } \\
\hline & Ranking & Induction coefficient & Ranking & Induction coefficient \\
\hline 1997 & 16 & 1.092184 & 25 & 0.682618 \\
\hline 2002 & 4 & 1.916266 & 39 & 0.444002 \\
\hline 2007 & 9 & 1.468016 & 41 & 0.381785 \\
\hline 2010 & 6 & 1.603254 & 37 & 0.378329 \\
\hline
\end{tabular}

Source: National Bureau of Statistics of China 


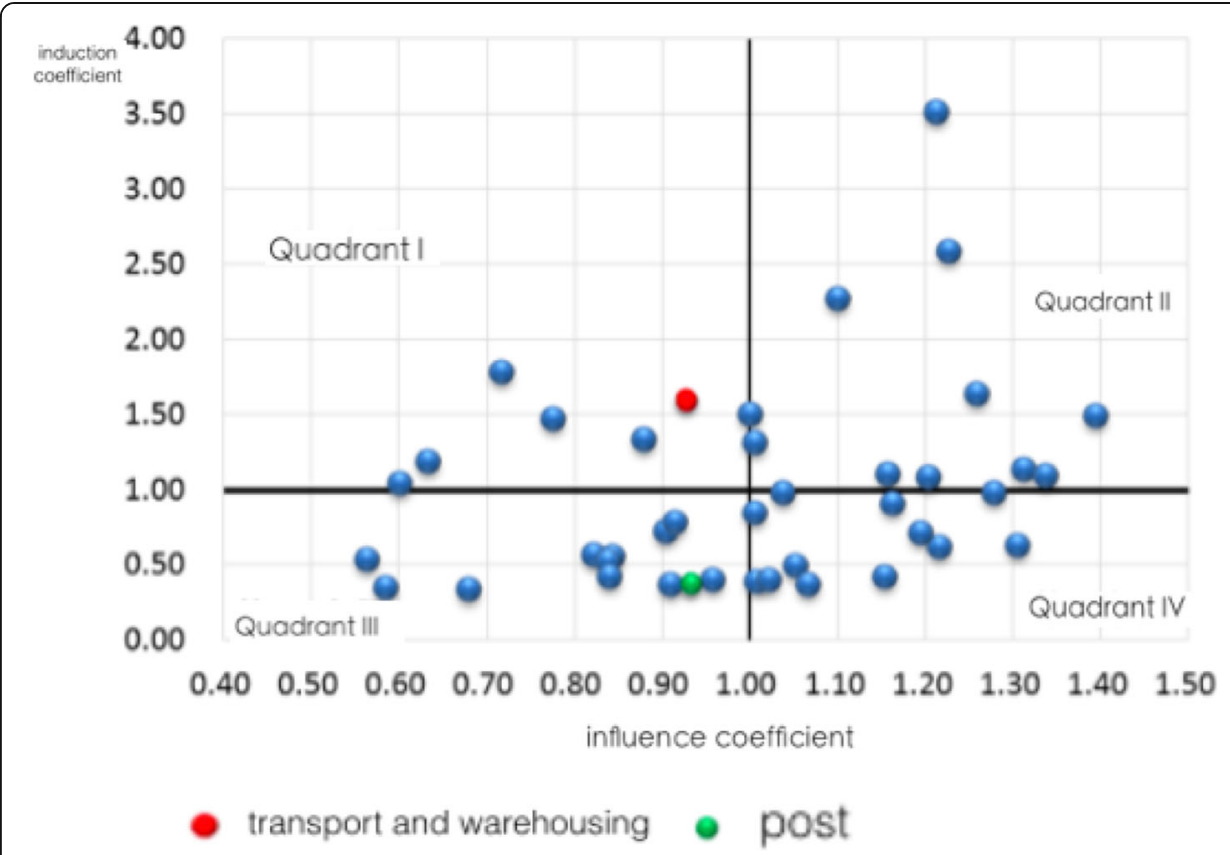

Fig. 12 The chart of influence coefficient-induction coefficient of all industrial sectors in 2010. Source: National Bureau of Statistics of China

the opportunity to develop the logistics service industry, and promote China's logistics industry's restructuring and upgrading.

\section{Results and discussion}

By investigating into input-output tables of the four periods from 1997 to 2010, the relationship between logistics industry and related industries can be analyzed. The trend of the development degree of logistics industry and its correlation degree with relative industries can be seen. Thus the theoretical basis for scientific judgment on logistics industry's status and its influence on national economy is provided. By calculating the direct consumption coefficient of each industry's sector against logistics and the direct consumption coefficients of the logistics industry against various sectors, and middle demand rate as well as middle input rate, the author of this thesis gains the following conclusions.

\section{The position of logistic industry remains to be further promoted}

Judging from the analysis into the features and involvement of logistics industry, the influence coefficients of logistics industry have risen slightly compared with the figure in 1997. This suggests that the influence of the logistics industry on the national economy is gradually expanding. The intermediate demand rate, influence coefficients, and induction coefficients have all risen in a small margin, showing the position of logistics industry is increasingly important in the whole national economy. In 2010, the intermediate rates of transportation and warehousing and the postal service industries have all exceeded 0.85 , meaning that products of logistics industry have been invested into the production 
process in the form of intermediate products and proving that logistics industry provides support for other industries.

But on the rankings of the influence coefficients of the whole logistics industry, the rankings of logistics industry's 40 industrial sectors are all at the middle and low levels. Through investigating into the changes on the rankings of the inputoutput tables from 1997 to 2010, we can see that during this period the influence of logistics industry has increased, but its involvement and influence degree is much lower than the average level, implying that logistics industry has yet to be further developed.

\section{Logistics industry becomes a sector with "low added value and strong leading force"}

According to the calculation results of intermediate demand rates and intermediate input rates of the logistics industry, the intermediate demand rates and the intermediate input rates of transportation and warehousing and postal service in our country have risen slightly compared with that of 1997. In particular, the nature as an industry of logistics industry since 2002 has been changed fundamentally from an industrial sector with "high added value and weak leading force" to one with "low added value and strong leading force." Its leading role in national economic development is mainly exemplified at providing complete integration of the supply chain for upstream and downstream enterprises and optimizing the circulation enterprises' offline channels. This indicates that logistics industry as a fundamental service sector in the national economy becomes increasingly obvious, and its leading force in promoting other sectors of national economy is stronger.

\section{Transition from domination by industrial logistics to service-oriented logistics}

Combining all the cross analysis results of various sectors, it can be seen that the secondary industry remains the major consumer of the intermediate demand amid the logistics industry. It mainly depends on secondary industries such as oil processing, coking and nuclear fuel processing, transportation equipment manufacturing, and general and special equipment manufacturing. And these industries not only are attached with dual attributes of strong influence and restrictive capability but also are the upstream industries of transportation and warehousing industries. The logistics industry highly depends on the development of the secondary industry and is being influenced and restricted greatly by these industrial sectors. As the transportation and warehousing industry as well as their correlated industries are mainly concentrated on the second industry, we should coordinate transportation and warehousing industry in order to adapt to the secondary industry, to seize the opportunity to develop service-oriented logistics vigorously, and to promote the structural adjustment and upgrading of our country's logistics industry.

With logistics industry correlation in 1997, the top five industries belong to the industrial sector began in 2002, the top five sectors financial industry and the third industry, such as wholesale and retail trade sector, lease, and commodity services since 2007, joined the comprehensive technical services, suggests that the third sector gradually expanding demand for logistics industry directly, also means that the focus of China's logistics industry is gradually from the industrial logistics to logistics service industry, which not only conforms to the direction of the national economy development but also promotes economic restructuring. 


\section{Logistics industry is closely related to the secondary industry}

Adding all the results of cross-association analysis of various industrial sectors together, we can conclude that the second industry at present is still the main consumer of the intermediate demand among logistics center line. It is especially dependent on the second industry of oil processing and coking and nuclear fuel processing industry, transportation equipment manufacturing, general and special equipment manufacturing industry; all of which have dual attributes of strong influence and strong restriction ability and are upstream industries of the transportation and warehousing industry. The logistics industry is highly dependent on the development of the second industry, and at the same time, it is constrained by the strong impact and restriction from these sectors. Given that the relevant industries of China's transportation and warehousing industry are mainly focused on the secondary industry, we should coordinate the transportation and warehousing industry in order to adapt themselves to the secondary industry, to seize the opportunity to develop the logistics service industry, and to promote China's logistics industry's restructuring and upgrading.

\section{Conclusions}

In view of the current situation of the development of logistics industry and the analysis and the above conclusions, this paper puts forward the following suggestions:

Firstly, the third party logistics should be developed vigorously to promote the socialization and specialization level of logistics distribution, with an aim of improving the efficiency of logistics. Development of socialization and specialization of logistics can make the distribution of resources concentrated as a large-scale, lower unit distribution costs and improve the management efficiency. At present, our country's third party logistics is still in its infancy with a small-scale and a low market share. It is recommended that advantage resources of various logistics enterprises should be integrated, and a large third-party logistics enterprises be established; the information platform of third party logistics should be used to integrate modules such as inventory management, shipping management, goods reception management, financial management, collection on delivery management, management on bank's payment of salaries, data transmission, and business decision, providing the service of tracking the whole process of logistics. In addition, clients are provided with individualized service such as logistics plans, resolutions to problems, management on circulation processing, and supply chain to improve their satisfaction and loyalty. Moreover, through intensive operations, logistics distribution is improved and the scale of logistics distribution is enlarged to reduce logistics costs.

Secondly, development of e-commerce logistics should be accelerated. Attention should be given to the construction and planning of logistics infrastructures including central cities, transportation hub, goods distribution center, and port area. We should fully consider the cohesion of goods distribution channels of each mode of transport and their overall matching with the comprehensive function of logistics facilities. Consideration also needs to be given to needs of both short-term and long-term development as well as the combination of management on hardware construction and software management. In the construction of logistics infrastructure, the role of market mechanism should be given full play to. On the basis of comprehensive planning and sufficient demonstration, it is encouraged that domestic investors and foreign investors 
take part in the construction of logistics base (logistics center), the government department construct logistics infrastructure concerning public welfare. Preferential policies shall also be provided by authorities in such aspects as land, capita, and tax. Construction of large logistic parks and large logistic centers must be planned well as key projects, while the layout of transportation infrastructure must be reasonable and logistics entities network be built.

Thirdly, informatization and standardization of logistics industry must be sped up and management and service level of logistics enterprises be improved. Informatization of logistics industry includes two aspects: one is the construction of a national or regional logistics information platform to perfect the integration of distribution network for real-time transmission of tracking information in goods distribution, which means the realization of the information network by the central or local government; the other is the construction of enterprises' logistics information management system that is completed by enterprises. Logistics standardization mainly includes the standardization of logistics tools and equipment, logistics information transmission, packing specifications, and the standardization on logistics operation and service.

\section{Acknowledgements}

The authors would like to acknowledge the financial support from the National Academy of Economics Strategy, CASS. (Grant No.: 2016CJYCX07).

This thesis is a periodical research result of Research into the Expanded Consumption Problems in China's 13th Year Plan, an innovative project presided by Yi Shaohua, a researcher of Financial Strategy Institute in Chinese Academy of Social Sciences.

Funding

Institution: National Academy of Economics Strategy, China Academy of Social Sciences. Grant number: 2016CJYCX07 Recipient: Shaohua Yi.

\section{Authors' contributions}

All listed authors have made substantial contribution to the following aspects of the manuscript. SY put forward the idea, created the theoretical models, and made the conclusions. JX mainly focused on the mathematical model and data processing. Both authors read and approved the final manuscript.

\section{Competing interest}

The authors declare that they have no competing interests.

\section{Authors' information}

Shaohua Yi is a research fellow, a Ph.D. of economics, and the research director of Circulation Industry Department in the National Academy of Economics Strategy, CASS. Her main research fields are circulation theory and policy, consumer issues, and circulation of agricultural products. Her email address is yishh@cass.org.cn

Jie Xie, a Ph.D. of economics and an associate professor in School of Economics of Zhejiang Gongshang University. His research interests are international trade and investment, spatial econometrics. His email address is X_j3027@sina.com

\section{Author details}

${ }^{1}$ Circulation Industry, Financial Strategy Institute, Chinese Academy of Social Sciences, Beijing, China. ${ }^{2}$ School of

Economics, Zhejiang Gongshang University, Hangzhou, China.

Received: 19 April 2017 Accepted: 16 August 2017

Published online: 22 September 2017

References

Leontief W (1990) Economics of input and output. Translated by Cui Shuxiang. Beijing: China statistical publishing house

Liang H, Wang J (2013) The research into the industrial correlation between logistics industry and manufacturing industry-comparative analysis basing on input-output tables. J Fujian Norm Univ (Edition of philosophy and social sciences) 2:71-72

Shao Y, Liang L, Zhang Y (2009) Analysis into the correlation of logistics industry with other industries basing on input and output. J Chang Univ Sci Technol 22(3):395-396

Wang H (2007) Analysis into the development features of China's logistics industry basing on input-output theory. Dalian Maritime University, Liaoning, pp 23-26

Wei M, Wang L, Li Y (2009) Studies into the association and the ripple effect of modern logistics industry's development. Journal of Business Economics,2009, (12): 17-18 